\title{
Gebelikte Prenatal Bağlanma ve Vücut Algısı Arasındaki İlişki ve Etkileyen Faktörler
}

\section{Relationship between Prenatal Attachment and Body Sense in Pregnancy and Affecting Factors}

\author{
Tuba Koç Özkan ${ }^{1 *}$, Didem Şimşek Küçükkelepçe ${ }^{1}$, Semiha Aydın Özkan ${ }^{1}$ \\ ${ }^{1}$ Adıyaman Üniversitesi Sağlık Yüksekokulu Ebelik Bölümü, Adıyaman, Türkiye \\ e-mail: tubakocozkan@gmail.com,koctuba85@gmail.com \\ Orcid: 0000-0003-4740-147X \\ Orcid: 0000-0003-0001-2581 \\ Orcid: 0000-0003-4538-0396 \\ *Sorumlu Yazar / Corresponding Author: Tuba KOÇ ÖZKAN \\ Gönderim Tarihi / Received:14.02.2019 \\ Kabul Tarihi / Accepted: \\ DOI: $10.34087 /$ cbusbed.587467 \\ Öz
}

\begin{abstract}
Amaç: Araştırma, gebelikte prenatal bağlanma ve vücut algısı arasındaki ilişki ve etkileyen faktörleri belirlemek amaciyla yapıld1.

Gereç ve Yöntem: Tanımlayıcı ve kesitsel tipte yapılan araştırma, Temmuz-Aralık 2017 tarihleri arasında Güneydoğu'da bulunan bir ilin kadın doğum ve çocuk hastanesi gebe izlem polikliniğine başvuran 195 gebe ile yürütüldü. Veriler; Tanıtıcı Özellikler Formu, Prenatal Bağlanma Ölçeği (PBE) ve Vücut Algısı Ölçeği (VAÖ) kullanılarak araştırmacılar tarafından yüz yüze görüşme yöntemi ile toplandı. Tanımlayıcı istatistikler frekans, yüzde, ortalama, standart sapma, bağımsız gruplar için t testi, Oneway ANOVA ve Pearson Korelasyon Analizi kullanıldı. Bulgular: Araştırmaya katılan gebelerin prenatal bağlanma puan ortalamalarının 43,84 $\pm 9,71$, vücut algısı ölçeği puan ortalamalarının 94,03 $\pm 20,35$ olduğu ve aralarında anlamlı bir ilişki olmadığı belirlendi. 31 yaş üstü $(45,85 \pm 9,78)$, ilköğretim mezunu $(46,30 \pm 9,51)$, gebelik sayısı 3 ve üzeri olan $(45,83 \pm 9,46)$ kadınlarda prenatal bağlanma puan ortalamalarının daha yüksek olduğu bulundu $(\mathrm{p}<0,05)$. Gebelerin vücut algısı ölçeği puanlarına yaş, eğitim durumu, ekonomik durum, gebelik haftası, gebelik sayısı, düşük, planlanmış gebelik ve bebeğin cinsiyeti ile ilişkisi olmadığı belirlendi.

Sonuç: Gebelerin PBE ile VAÖ arasında bir ilişki olmadığı saptandı. Gebelerin, eğitim düzeyinin yükselmesi PBE’yi olumsuz yönde etkilerken, yaşın artması, üç ve üzeri gebeliği olan kadınların PBE puanlarının daha yüksek olduğu belirlendi. VAÖ puanlarının ise sosyo-demografik özelliklerden etkilenmediği görüldü.
\end{abstract}

Anahtar Kelimeler: Bağlanma, beden imaj1, gebelik

\begin{abstract}
Aim: The aim of the study was determined the factors affecting prenatal attachment and body perception levels of the pregnant women.

Method and Materials: The study was conducted with 195 pregnant women who applied to the pregnancy followup policlinic in an obstetric gynecology and pediatric hospital in Southeast of Turkey between July and December 2017. The data were collected by face to face interview using the Personal Information Form, Prenatal Attachment Invantory (PAI) and Body Cathexis Scale (BCS). In evaluation of the data, frequency, percentage, mean, standard deviation, t-test for independent groups, ANOVA and Pearson Correlation Analysis were used.

Results: Prenatal attachment score of the women was found to be $43.84 \pm 9.71$ and body perception score was 94.03 \pm 20.35 and there was no significant relationship between them. The mean PAI scores of women aged 31 and older, had primary school graduate, had three and more pregnancy were found to be higher $(\mathrm{p}<0.05)$. There was no statistically significant relationship between BCS scores of pregnant women and their age, educational status,
\end{abstract}


economic status, abortion status, abortion history, number of pregnancies, number of living children, planned pregnancy, gestational week and the sex of the baby.

Conclusion: It was determined that there was no relationship between pregnant PAI and BCS. While the increase in education level of the pregnant women was affecting the PAI negatively, it was determined that the PAI scores of the women aged 31 and older and had three or more gestations. It was observed that BCS scores were not affected by socio-demographic characteristics.

Keywords: Attachment, body image, pregnancy

\section{Giriș}

Prenatal dönem, fizyolojik değișimlerin yaşandığı bir dönem olmasına rağmen psikolojik ve duygusal değişimler de yaşanabilmektedir $[1,2]$. Prenatal dönemde gebe ile fetüs arasındaki bağlanma, gebeliğe uyumu kolaylaştıran ve bebekle kurulan ilk önemli ilişki olup, doğum sonrasında anne-çocuk ilişkisinde belirleyici bir rol oynamaktadır [1, 3]. Oluşan bu ilişki/bağlılık prenatal bağlanma olup, ebeveynler ve doğmamış çocukları arasında kurulan duygusal bir bağ olarak tanımlanmaktadır. Gebe ile bebeği arasındaki bağlanma gebeliğin yaklaşık 10. haftasında kurulmaya başlar ve gebenin bebeğinin hareketlerini hissetmesiyle ortaya çıkmaktadır [4]. Prenatal bağlanma düzeyi yüksek olan gebe doğmamış bebeği ile bağ kurduğuna inanır ve fetüsü ayrı bir kişi olarak görür [1, 5]. Gebelikte yaşanan bu değişiklikler ile birlikte prenatal bağlanma birçok faktörden etkilenebilmektedir. Yapılan çalışmalarda öğrenim düzeyinin, çalışma durumunun, paritenin, doğum öncesi eğitim alma durumunun, gebeliğin istendik olma durumunun, gebelik haftasının, fetal hareketlerin hissedilmesi, gebelik döneminde yaşanan stres ve kaygı ile baş edebilme tarzlarının, gebelikte meydana gelen fiziksel değişikliklerin, beden imajını algılarının, gebelerin duygusal zekalarının ve sosyal destek algılarının prenatal bağlanmayı etkilediği görülmüştür [2, 3, 6-8].

Vücut algısı bebeklikte başlayarak yaşam boyu gelişen, değişen ve kişinin kendi bedeni ile ilgili olarak zihninde şekillendirdiği öznel algılaması ile ilişkili dinamik bir kavramdır. Kadınlarda vücut algısı özellikle ergenlik, gebelik, doğum sonu ve menopoz gibi dönemlerden etkilenmektedir [9]. Gebelik sürecinde yeni ve farklı durumlara uyum sağlamaya çalışan kadınların, bu dönemde aldığı kilolar, cildinde meydana gelen değişikliklerin sonucunda vücut algısı da değişmektedir [10]. Gebelikte yaşanan bu değişiklikleri kadınlar çoğunlukla olumlu karşılamakta ve uyum sağlamaktadırlar. Ancak bu değişimler bazı kadınlarda olumsuz vücut algısına neden olabilmektedir. Özellikle gebeliğin 3 . ve 6 . ayları arasında olumsuz vücut algıs1, zayıf anne- bebek bağlanması ile ilişkilidir [11].

$\mathrm{Bu}$ araştırmada, vücut algısı yüksek olan gebelerin prenatal bağlanma düzeylerinin de yüksek olacağı düşüncesi ile gebelerin prenatal bağlanma ve vücut alg1sı arasındaki ilişki ve etkileyen faktörler incelenmiştir. Literatür incelendiğinde hem prenatal bağlanma hem de gebelikteki vücut algıları konusunda çalışmalara rastlanılmıştır. Ancak gebelerin prenatal bağlanma ve vücut algısı düzeylerini etkileyen faktörlerin birlikte incelendiği sınırlı sayıda çalışmaya rastlanmıştır $[11,12]$.
Bu bilgilerden yola çıkarak araştırma, gebelerde prenatal bağlanma ve vücut algısı arasındaki ilişki ve etkileyen faktörlerin incelenmesi amacı ile yapıldı.

\section{Gereç ve Yöntem}

2.1. Araştırmanın Yeri ve Zamanı: Araştırma, TemmuzAralık 2017 tarihleri arasında Güneydoğu'da bulunan bir ilin kadın doğum ve çocuk hastanesi gebe izlem polikliniğine başvuran gebeler ile yürütüldü.

\subsection{Araştırmanın Evreni ve Örneklemi: Araştırmanın} evrenini, Güneydoğu'da bulunan bir ilin kadın doğum ve çocuk hastanesi gebe izlem polikliniğine başvuran gebeler oluşturdu. Örneklem büyüklüğü G-Power 3.1.9 programı ile hesaplandı. Araştırmada \%95 güven aralığ 1 , 0.05 anlamlılık düzeyinde yapılan güç analizinde çalışma gücü 0.95 , etki büyüklüğü ise 0.23 alındığında örneklem büyüklüğü 195 olarak bulundu. Araştırma; 18 yaş ve üstü, 20. gebelik haftasından büyük, kronik bir hastalığ1 olmayan, iletişim sorunu ve mental bir hastalığı olmayan, sağlıklı bir gebelik geçiren, sağlıklı ve tek fetüsü olan ve araştırmaya katılmayı kabul eden gebeler ile yürütüldü.

2.3. Araştırmanın Tipi: Araştırma gebelerde prenatal bağlanma ve vücut algısı arasındaki ilişki ve etkileyen faktörlerin incelenmesi amacı ile tanımlayıcı ve kesitsel olarak gerçekleştirildi.

2.4. Veri Toplama Araçları: Verilerin toplanmasında, 'Tanıtıcı Özellikler Formu',, 'Prenatal Bağlanma Ölçeği', ve "'Vücut Algısı Ölçeğii" kullanıldı.

2.4.1. Tanıtıcı Özellikler Formu: Araştırmacılar tarafından literatür doğrultusunda oluşturulan formda [10,13-16] gebelerin sosyo-demografik özellikleri ile önceki ve şimdiki gebeliklerine ilişkin özellikleri içeren toplam 13 soru yer almaktayd1.

2.4.2. Prenatal Bağlanma Envanteri (PBE): Envanter, kadınların gebelik süresince yaşadıkları duygularını, düşüncelerini ve prenatal dönemde bebeğe bağlanma düzeylerini belirlemek amaciyla 1993 yılında Muller tarafından geliştirilmiştir. Dörtlü likert tipte, 21 maddeden oluşan envanterden 21 ile 84 arasında puan alınabilmektedir. Envanterden alınan puanın artması prenatal bağlanma düzeyinin de arttığını göstermektedir. Ölçeğin Türkçe geçerlik ve güvenirliği 2013 yılında Yılmaz ve Beji tarafından yapılmış ve iç tutarlılık kat sayısı 0,84 olarak bildirilmiştir [1]. Bu araştırmada ölçeğin iç tutarlılık katsayısı 0,83 olarak bulunmuştur. 
2.4.3. Vücut Algısı Ölçeği (VAÖ): Secord ve Jourard tarafından 1953 yılında geliştirilen ölçek, 40 maddeden oluşmakta olup, her bir madde vücudun bir bölümü, bir organı ya da bir işlevi ile ilgili memnuniyet durumunu belirleyen sorular yer almaktadır. Beşli likert tipte hazırlanan ölçekten en az 40, en fazla 200 puan alınabilmekte olup, alınan puanın yüksekliği doyumun azaldığını ifade etmektedir. Ölçeğin Türkçe geçerlik ve güvenirliği 1989 yılında Hovardaoğlu tarafından yapılmış ve iç tutarlılık kat sayısı 0,91 olarak bildirilmiştir [17]. Bu araştırmada ölçeğin iç tutarlılık katsayısı 0,90 olarak bulunmuştur.

2.5. Verilerin Toplanması: Veriler, araştırmacılar tarafından gebelere araştırma ile ilgili bilgi verildikten sonra yüz yüze görüşme yöntemi ile yaklaşık 20-30 dakikada topland1.

2.6. Araştırmanın Sinırlılıkları: Araştırmanın tek bir hastanede yapılması ve kesitsel nitelikte olmasından dolayı ülkedeki tüm gebelere genellememektedir.

2.7. Araştırmanın Etik Boyutu: Araştırmanın yapılabilmesi için Adıyaman Üniversitesi Tıp Fakültesi'nden 20.06.2017 tarihli ve 2017/5-11 sayılı etik kurul izni alındı.

2.8. Verilerin Analizi: Araştırma verileri SPSS 17 (Statistical Package for Social Sciences) programı ile değerlendirildi. Araştırmadan elde edilen verilerin analizi yapılmadan önce verilerin normal dağılıma uygunluğu Kolmogorov-Smirnov, Shapiro Wilks testleri ile kontrol edildi. Verilerin değerlendirilmesinde; tanımlayıc1 istatistikler (frekans, ortalama, standart sapma), bağımsız gruplar için $t$ testi, Oneway ANOVA ve Linear Regresyon Analizi kullanıldı.

\section{Bulgular}

Araştırmaya katılan gebelerin prenatal bağlanma puanlarının 43,84 $\pm 9,71$ ve vücut algısı ölçeği puanlarının $94,03 \pm 20,35$ olduğu belirlendi (Tablo 1).

Tablo 1. Gebelerin PBE ve VAÖ Puan Ortalamaları $(\mathrm{n}=195)$

\begin{tabular}{|c|c|}
\hline PBE & VAÖ \\
\hline Ort \pm SS & Ort \pm SS \\
\hline $43,84 \pm 9,71$ & $94,03 \pm 20,35$ \\
\hline
\end{tabular}

Gebelerin prenatal bağlanma envanteri ile vücut algis1 ölçeği puanları arasında anlamlı bir ilişki olmadığg saptand (Tablo 2).

Tablo 2. Gebelerin PBE Ve VAÖ Arasındaki İlişki $(\mathrm{n}=195)$

\begin{tabular}{|l|c|c|}
\hline \multirow{2}{*}{ Ölçekler } & \multicolumn{2}{|c|}{$\begin{array}{c}\text { Prenatal Bağlanma } \\
\text { Ölçeği }\end{array}$} \\
\cline { 2 - 3 } & $\mathbf{r}$ & $\mathbf{p}$ \\
\hline Vücut Algısı Ölçeği & 0,104 & 0,147 \\
\hline
\end{tabular}

Pearson Korelasyon Analizi, $\mathrm{p}<0.05, \mathrm{p}<0.001$
Araştırmaya katılan gebelerin yaş ortalaması 29,71 $\pm 6,01$ (min18-maks45) ve \%54,9'u 18-30 yaş arasındadır. Ortalama gebelik haftas1 $34,60 \pm 4,38$ (min 20-maks 41)'dır. Gebelerin \%62,6'sını lise ve üstü mezunu olduğu ve \%84,6'sının gelirinin giderlerine eşit olduğu belirlendi. Gebelerin büyük çoğunluğunun daha önce hiç kürtaj olmadığ $1 \% 83,6)$ ve düşük deneyimi yaşamadığ 1 $(76,9), \% 48,7$ 'sinin üç ve üzerinde gebelik yaşadığı ve \%76,4'ünün bir ve üzerinde yaşayan çocuğunun olduğu saptandı. Ayrıca gebelerin büyük çoğunluğunun planlayarak gebe kaldığ $1(\% 82,1)$ ve üçüncü trimesterde olduğu $(\% 91,8)$, yarısından fazlasının gebelik süresince $1-12 \mathrm{~kg}$ arasında kilo aldığ $(69,7)$ ve yarıya yakın bir bölümünün bebeğinin cinsiyetinin erkek olduğu $(\% 48,2)$ belirlendi (Tablo 3).

Gebelerin tanıtıcı özellikleri ile PBE puanları arasındaki ilişki değerlendirildiğinde; 31 yaş ve üzeri, ilköğretim mezunu olan, üç ve üzeri gebeliği olan kadınların PBE puan ortalamalarının daha yüksek olduğu bulundu $(\mathrm{p}<0,05)$. Yaş ve gebelik sayısı ile PBE puanı arasında istatistiksel açıdan anlamlı pozitif doğrusal bir ilişki olduğu (sırasiyla $\mathrm{t}=2.654, \mathrm{p}=0,009 ; \mathrm{t}=2.741, \mathrm{p}=0,007$ ), eğitim durumu ile PBE puanı arasında istatistiksel açıdan anlamlı negatif doğrusal bir ilişki olduğu belirlendi ( $\mathrm{t}=$ 2.775, p=0,006). Gebelerin PBE puanı ile ekonomik durum, düşük deneyimi, kürtaj olma durumu, planlanmış gebelik, gebelik haftası ve bebeğin cinsiyeti arasında ise istatistiksel olarak anlamı bir ilişki bulunmadığ belirlendi ( $p>0,05)$ (Tablo 3). Gebelerin VAÖ puanı ile yaş, eğitim durumu, ekonomik durum, kürtaj olma durumu, düşük öyküsü, gebelik sayısı, yaşayan çocuk sayısı, planlanmış gebelik, gebelik haftası ve bebeğin cinsiyeti karşılaştırıldığında ise istatistiksel olarak anlamlı bir ilişki bulunmadığı saptandı $(\mathrm{p}>0,05)$ (Tablo $3)$.

\section{Tartışma}

Kadınların annelik rolünü kazanmasında ve doğum sonunda anne ile bebek arasındaki emosyonel bağın kurulmasında prenatal dönem önemli rol oynamaktadır $[18,19]$. Prenatal bağlanmayı yaş, eğitim düzeyi, ekonomik durum, önceki fetüs kayıpları, planlanmamış gebelik, gebelik sayısı, gebelik haftası ve bebeğin cinsiyeti gibi faktörler etkileyebilmektedir $[1,15]$. Aynı zamanda gebelik haftasının artmasıyla vücutta meydana gelen değişimlerde prenatal bağlanmayı etkileyebilmektedir. Huang ve arkadaşlarının yaptıkları çalışmada (2004) vücut algısı ile PBE arasında ilişki olduğu, vücut algısı puanı düşük olan gebelerin PBE puanlarının daha düşük olduğu bildirilmiştir. $\mathrm{Bu}$ araştırmada PBE puanları 43,84 $\pm 9,71$, vücut algısı puanları 94,03 $\pm 20,35$ olduğu ve aralarında ilişki olmadığı saptandı.

Kadınların annelik rolünü kazanması ve fetüse bağlanmada annenin yaşı etkili olmaktadır [20]. Ossa ve arkadaşlarının 243 gebe ile yaptıkları çalışmada (2012) ve Elkin ve arkadaşlarının 142 gebe ile yaptıkları çalışmada (2015) anne yaşı ile PBE puanları arasında istatistiksel olarak anlamlı fark olmadığı bildirilmiştir. 
Tablo 3. Gebelerin Tanıtıcı Özellikleri İle PBE ve VAÖ Arasındaki İlișki (n=195)

\begin{tabular}{|c|c|c|c|c|c|c|}
\hline \multirow{2}{*}{ Tanıtıcı özellikler } & \multicolumn{2}{|c|}{ Sayı } & \multicolumn{2}{|c|}{ PBE } & \multirow{2}{*}{$\begin{array}{c}\text { VAÖ } \\
\text { Ort } \pm \text { SS }\end{array}$} & \multirow[b]{2}{*}{ p } \\
\hline & n & $\%$ & Ort \pm SS & $\mathbf{p}$ & & \\
\hline \multicolumn{7}{|l|}{ Yaş } \\
\hline $18-30$ yaş & 107 & 54,9 & $42,19 \pm 9,39$ & \multirow{2}{*}{0,009} & $93,14 \pm 18,83$ & \multirow{2}{*}{0,506} \\
\hline 31 yaş ve üzeri & 88 & 45,1 & $45,85 \pm 9,78$ & & $95,10 \pm 22,12$ & \\
\hline \multicolumn{7}{|l|}{ Eğitim durumu } \\
\hline İlköğretim & 73 & 37,4 & $46,30 \pm 9,51$ & \multirow{2}{*}{0,006} & $94,68 \pm 20,29$ & \multirow{2}{*}{0,729} \\
\hline Lise ve üstü & 122 & 62,6 & $42,37 \pm 9,5$ & & $93,63 \pm 20,46$ & \\
\hline \multicolumn{7}{|l|}{ Ekonomik durum } \\
\hline Geliri giderden az & 30 & 15,4 & $44,90 \pm 8,89$ & \multirow{2}{*}{0,520} & $98,33 \pm 15,21$ & \multirow{2}{*}{0,209} \\
\hline Geliri gidere eşit & 165 & 84,6 & $43,65 \pm 9,87$ & & $93,24 \pm 21,10$ & \\
\hline \multicolumn{7}{|l|}{ Kürtaj öyküsü } \\
\hline Var & 32 & 16,4 & $43,28 \pm 8,74$ & \multirow{2}{*}{0,720} & $94,43 \pm 14,34$ & \multirow{2}{*}{0,873} \\
\hline Yok & 163 & 83,6 & $43,95 \pm 9,92$ & & $93,95 \pm 21,37$ & \\
\hline \multicolumn{7}{|l|}{ Düşük öyküsü } \\
\hline Var & 45 & 23,1 & $46,00 \pm 9,84$ & \multirow{2}{*}{0,09} & $91,40 \pm 16,51$ & \multirow{2}{*}{0,324} \\
\hline Yok & 150 & 76,9 & $43,20 \pm 9,62$ & & $94,82 \pm 21,26$ & \\
\hline \multicolumn{7}{|l|}{ Gebelik sayısı } \\
\hline 1 & 42 & 21,5 & $41,42 \pm 10,6$ & \multirow{3}{*}{0,018} & $89,23 \pm 22,49$ & \multirow{3}{*}{0,228} \\
\hline 2 & 58 & 29,7 & $42,34 \pm 8,91$ & & $95,25 \pm 18,49$ & \\
\hline 3 ve üzeri & 95 & 48,7 & $45,83 \pm 9,46$ & & $95,40 \pm 20,34$ & \\
\hline \multicolumn{7}{|l|}{ Planlanmış gebelik } \\
\hline Evet & 160 & 82,1 & $43,23 \pm 9,44$ & \multirow{2}{*}{0,610} & $93,15 \pm 20,89$ & \multirow{2}{*}{0,197} \\
\hline Hayır & 35 & 17,9 & $46,62 \pm 10,60$ & & $98,05 \pm 17,37$ & \\
\hline \multicolumn{7}{|l|}{ Gebelik haftası } \\
\hline 2. trimester & 16 & 8,2 & $41,00 \pm 7,76$ & \multirow{2}{*}{0,222} & $89,56 \pm 15,73$ & \multirow{2}{*}{0,126} \\
\hline 3. trimester & 179 & 91,8 & $44,10 \pm 9,85$ & & $94,69 \pm 20,62$ & \\
\hline \multicolumn{7}{|l|}{ Bebeğin cinsiyeti } \\
\hline Bilinmiyor & 18 & 8,2 & $44,81 \pm 11,87$ & & $96,12 \pm 16,59$ & \\
\hline $\mathrm{K}_{1 \mathrm{z}}$ & 85 & 43,6 & $43,10 \pm 9,77$ & & $92,52 \pm 21,80$ & 0,653 \\
\hline Erkek & 94 & 48,2 & $44,35 \pm 9,32$ & 0,742 & $95,03 \pm 20,35$ & \\
\hline Toplam & 195 & 100,0 & $43,84 \pm 9,71$ & & $94,03 \pm 20,35$ & \\
\hline
\end{tabular}

t-testi, Oneway ANOVA $\mathrm{p}<0.05, \mathrm{p}<0.001$

Bu çalışmaların aksine Bakır ve arkadaşlarının (2014) 160 riskli gebe ile yaptıkları çalışmada 18-30 yaş arasındaki gebelerin PBE puanlarının, Çınar ve arkadaşlarının (2017) 211 gebe ile yaptıkları çalışmada 18-29 yaş arasındaki gebelerin PBE puanlarının istatistiksel olarak anlamlı fark ile daha yüksek olduğu belirlenmiştir. Benzer şekilde bu araştırmada da anne yaşı ile PBE puan ortalamaları arasında bir ilişki saptand1.

Ancak yapılan çalışmaların aksine araştırmamızda 30 yaş üstü gebelerin PBE puanları daha yüksek bulundu. Bağlanma, bireyin yaşı ile birlikte inançlarından geçmiş deneyimlerinden, çevresel ve kültürel faktörlerden etkilenebilir [22]. Farklı toplumlarda farklı örneklem grupları ile yapılan çalışmalarda yaş faktörü ile bağlanma arasında ilişki olduğunu ve bağlanmanın yaş ile birlikte birçok faktörden etkilendiğini bu durumu bireyin yetiştiği sosyo-kültürel yapı ile ele alınması gerektiği yönünde düşünülebilir.

Literatürde eğitim seviyesinin PBE ile ilişkisi üzerine tam bir fikir birliğine varılamadığı ancak eğitim seviyesi ile prenatal bağlanma arasında ilişsi olduğunu ve olmadığını gösteren çalışmalar bulunmaktadır [2, 9, 14, 15, 21]. Bakır ve arkadaşlarının (2014), Höbek Akarsu ve Oksay'ın (2017) ve Çınar ve arkadaşlarının (2017) yaptıkları çalışmada eğitim düzeyi ile PBE arasında istatistiksel olarak anlamlı ilişki olduğu ve eğitim düzeyi arttıkça PBE puan ortalamalarının da arttığı bildirilmiştir. Elkin ve arkadaşlarının (2015) ve Aksoy ve arkadaşlarının (2016) yaptıkları çalışmada ise annenin eğitim düzeyi ile prenatal bağlanma açısından istatistiksel olarak anlamlı bir ilişki bulunmadığ belirlenmiștir. $\mathrm{Bu}$ araştırmada ise eğitim düzeyi düşük olan gebelerin PBE puanları daha yüksek bulundu. Temel demografik faktörlerden eğitim düzeyi ile prenatal bağlanma arasındaki ilişkinin bilinmesi ile ebe ve hemşireler tarafından, özellikle bağlanma düzeyi düşük olan gruplarda, bağlanma bozukluklarının anne ve bebek üzerine olan etkilerini önlemeye yönelik girişimlerin planlanması ve eğitimlerin verilmesi açısından önemlidir.

Gebelik sürecinde fetüsün kaybı kadınları emosyonel yönden olumsuz etkilemekle birlikte bir sonraki gebeliğe 
uyumu zorlaştırabilmektedir [23]. Vedove ve arkadaşlarının (2008) [23] ve Aksoy ve arkadaşlarının (2016) [2] yaptıkları çalışmada, abortus/kürtaj öyküsü ile prenatal bağlanma arasında ilişki olmadığı bildirilmiştir. Bakır ve arkadaşlarının (2014) [14] yaptıkları çalışmada ise abortus/kürtaj öyküsü olmayan gebelerin PBE puanlarının daha yüksek olduğu saptanmıştır. Buna karşın Höbek Akarsu ve Oksay'un (2017) [8] yaptıkları çalışmada, düşük/kürtaj öyküsü olan kadınların PBE puanlarının daha yüksek olduğu bildirilmiştir. Araştırmada ise düşük ve kürtaj öyküsü olan kadınların PBE puanları arasında fark olmadığı belirlendi.

Gebelik sayısının prenatal bağlanmaya etkisine yönelik farklı sonuçların yer aldığı çalışmalar bulunmaktadır. Bazı çalışmalarda [2, 3, 6, 15, 23] gebelik sayısı ile PBE arasında ilişki olmadığı bildirilmiştir. Buna karşın ilk kez gebe kalan kadınların PBE puanlarının daha yüksek olduğu saptanan çalışmalar da bulunmaktadır [8,14]. Bu araştırmada üç ve daha fazla gebelik yaşayan kadınların PBE puanlarının daha yüksek olduğu belirlendi. Bu sonuçlar literatürle farklılık göstermektedir.

Gebeliğin planlı olması prenatal bağlanmayı etkileyen önemli faktörlerdendir. Gebeliğe hazır olma ve bebeğe istenen zamanda sahip olma anne ile bebek arasındaki bağlanmayı arttırmaktadır [21,24]. Yapılan bazı çalışmalarda gebeliği planlı olanların PBE puanlarının daha yüksek olduğu bildirilmiştir [6,21]. Literatürde gebeliğin planlanma durumu ile PBE puanı arasında ilişki olmadığına yönelik çalışmalarda bulunmaktadır [2, $3,14,15]$. Bu araştırmada da literatüre benzer şekilde gebeliğin planlı olması ile PBE arasında ilişki saptanmad1.

Bebeğin istenilen cinsiyette doğması prenatal bağlanmayı olumlu yönde etkileyebilmektedir [1,5]. Abasi ve arkadaşlarının (2012) [20] yaptıkları çalışmada erkek bebeği olan annelerin bağlanma düzeylerinin daha yüksek olduğu bildirilmiştir. Araştırmamızda ise bebeğin cinsiyeti ile prenatal bağlanma arasında anlamlı bir ilişki olmadığı belirlendi. Sonuçların farklı çıkmasında araştırmanın yapıldığı popülasyonun sosyokültürel özellikleri ve değer yargılarının etkili olabileceği düşünüldü.

Gebelikte alınan kilolar, hormonal değişim algılanan vücut algısında değişikliğe yol açabilmektedir. Vücut algısının olumsuz etkilenmesinde gebenin içinde bulunduğu sosyokültürel faktörler etkili olabilmektedir [13]. Babacan ve Gümüş'ün yaptıkları çalışmada (2011) [9], geliri yetersiz olan gebelerin vücut algısının daha düşük olduğu belirlenmiştir. Çırak ve Özdemir'in yaptıkları çalışmada (2015) [10] geliri düşük olan, sosyal güvencesi olmayan ve plansız gebeliklerde gebelerin vücut algısı ölçeğinden aldıkları puanların daha düşük olduğu saptanmıştır. Bu araştırmada ise gebelerin tanıtıcı özellikleri ve vücut algısı puanları arasında anlamlı bir ilişki olmadığı bulundu.

\section{Sonuç ve Öneriler}

Araştırmada gebelerin prenatal bağlanmalarının ve vücut algılarının orta düzeyde olduğu bulundu. Gebelerin, eğitim düzeyinin yükselmesi PBE'yi olumsuz yönde etkilerken, yaşın artması, üç ve üzeri gebeliği olan kadınların PBE puanlarının daha yüksek olduğu belirlendi. VAÖ puanlarının ise sosyo-demografik özelliklerden etkilenmediği görüldü.

Araştırmadan elde edilen sonuçlar doğrultusunda; sağlık çalışanlarının, gebelerin prenatal bağlanma düzeylerini değerlendirmesi ve arttırması önerilmektedir. Aynı zamanda prenatal bağlanmayı ve vücut algısını etkileyen faktörleri belirlemeye yönelik çalışmaların farklı gebe gruplarında da yapılması önerilmektedir.

\section{Referanslar:}

1. Dereli Yılmaz, S, Kızılkaya Beji, N. (2013). Prenatal bağlanma envanterinin Türkçe'ye uyarlanması: Güvenilirlik ve geçerlilik çalışması. Journal of Anatolia Nursing and Health Sciences 2013, 16(2), 103-109.

2. Aksoy, E.Y., Yılmaz Dereli, et al. Riskli gebeliklerde prenatal bağlanma ve sosyal destek. Turkiye Klinikleri Journal Of Health Sciences 2016, 1(3),163-169.

3. Ossa, X, Bustos, L, et al. Prenatal attachment and associated factors during the third trimester of pregnancy in temuco, chile. Midwifery 2012, 28(5),689-96

4. Bekmezci H, Özkan H. Gebelikte psikososyal sağlık bakım, prenatal bağlanma ve ebe-hemșirenin sorumlulukları. Uluslararası Hakemli Kadın Hastalıkları ve Anne Çocuk Sağlı̆ı Dergisi 2016, 8,50-62.

5. Köse, D., Cınar, N., et al. Yenidoğanın anne ve baba ile bağlanma süreci. Merhaba 2013, 22(6), 239-245.

6. Dereli Yılmaz S, Kızılkaya Beji N. Gebelerin stresle başa çıkma, depresyon ve prenatal bağlanma düzeyleri ve bunları etkileyen faktörler. Genel Tip Dergisi 2010, 20(3), 99-108.

7. Chang, H. C, Yu, C. H, et al. The effects of music listening on psychosocial stress and maternal-fetal attachment during pregnancy. Complementary Therapies in Medicine 2015, 23(4), 509-515.

8. Höbek Akarsu, R, Oskay, Ü. Yüksek riskli gebelerin tehlike belirtileri hakkında bilgi ve prenatal bağlanma düzeylerinin belirlenmesi. Ege Üniversitesi Hemșirelik Fakültesi Dergisi 2017, 33(2), 16-26.

9. Babacan Gümüş, A., Çevik, et al. Gebelikte benlik saygısı ve beden imajı ile ilişsili özellikler. Anatolian Journal Of Clinical Investigation $2011,5(1), 7-14$

10. Cırak R., Özdemir F. Adölesan gebelerde beden imajı algısının belirlenmesi. Anadolu Hemşirelik ve Sağllk Bilimleri Dergisi 2015, 18,214-221.

11. Chang, S. R., Chao, Y. M., et al. I am a woman and I'm pregnant: body image of women in Taiwan during the third trimester of pregnancy. Birth 2006, 33(2), 147-153.

12. Huang, H.C., Wang, S.Y., et al. Body image, maternal-fetal attachment, and choice of infant feeding method: a study in taiwan, Birth 2004, 31(3),183-188.

13. Kumcagiz, H. Pregnant women, body image and self-esteem according to the examination of some of the variables. Journal of Human Sciences 2012, 9(2), 691-703.

14. Bakır, N., Ölçer, Z. et al Yüksek riskli gebelerin prenatal bağlanma düzeyi ve etkileyen faktörler. Uluslararası Hakemli Kadın Hastalıkları ve Anne Çocuk Sağlığı Dergisi 2014, 1(1),25-37.

15. Elkin, N. Gebelerin prenatal bağlanma düzeyleri ve bunlar etkileyen faktörler. Sürekli Tıp Eğitimi Dergisi 2015, 24(6),230-236. 16. Buko, G, Özkan, H. Gebelerin duygusal zekâları ile prenatal bağlanma düzeyleri arasındaki ilişki, Anadolu Hemşirelik ve Sağlık Bilimleri Dergisi 2016, 19(4),217-224

17. Hovardaoğlu, S. (1993). Vücut algısı ölçeği, Psikiyatri, Psikoloji, Psikofarmakoloji (3P) Dergisi 1993, 1(1), 26.

18. El-Hage, W, Le'ger, J, et al. Amniocentesis, maternal psychopathology and prenatal representations of attachment: A prospective comparative study. Plos One 2012, 7(7),1-9. 
19. Duyan, V, Gül Kapısız, S, et al. Doğum öncesi bağlanma envanteri'nin bir grup gebe üzerinde türkçeye uyarlama çalışması. The Journal of Gynecology-Obstetrics and Neonatology 2013; 10, 1609-14

20. Abasi, E, Tahmasebi, H, et al. Assessment on effective factors of maternal-fetal attachment in pregnant women. Life Science Journal 2012; 9,68-75

21. Çınar, N, Yalnızoğlu Caka S, et al. The relation of health-related practices of pregnant women, fatigue and prenatal attachment. Journal of the College of Physicians and Surgeons-Pakistan: JCPSP 2017, 27(11), 693-698

22. Torshizi, M. Different dimensions of maternal-fetal attachment behaviors and associated factors in pregnant women referred to health centers of birjand, İran. The Iran Journal of Obstetrics, Gynecology and Infertility 2013, 16(72),13-21.

23. Vedova, A.M.D., Dabrassi, F, et al. Assessing prenatal attachment in a sample of Italian women. Journal of Reproductive and Infant Psychology 2008, 26(2),86-98.

24. Yarcheski, A, Mahon, N.E, et al. A meta-analytic study of predictors of maternal-fetal attachment. International Journal of Nursing Studies 2009, 46,708-15.

http://edergi.cbu.edu.tr/ojs/index.php/cbusbed isimli yazarın CBU-SBED başlıklı eseri bu Creative Commons Alıntı-Gayriticari4.0 Uluslararası Lisansı ile lisanslanmıştır. 